\title{
Educação Ambiental: o desafio da construção de um pensamento crítico, complexo e reflexivo
}

Pedro Roberto Jacobi

Universidade de São Paulo

\section{Resumo}

A multiplicação dos riscos, em especial os ambientais e tecnológicos de graves conseqüências, é elemento chave para se entender as características, os limites e as transformações da nossa modernidade. É cada vez mais notória a complexidade desse processo de transformação de uma sociedade cada vez mais não só ameaçada, mas diretamente afetada por riscos e agravos socioambientais. Os riscos contemporâneos explicitam os limites e as conseqüências das práticas sociais, trazendo consigo um novo elemento, a "reflexividade". A sociedade, produtora de riscos, torna-se crescentemente reflexiva, o que significa dizer que ela se torna um tema e um problema para si própria. 0 conceito de risco passa a ocupar um papel estratégico para o entendimento das características, dos limites e das transformações do projeto histórico da modernidade e para reorientar estilos de vida coletivos e individuais. Num contexto marcado pela degradação permanente do meio ambiente e do seu ecossistema, isso envolve um conjunto de atores do universo educativo em todos os níveis, potencializando o engajamento dos diversos sistemas de conhecimento e a sua capacitação numa perspectiva interdisciplinar. Os educadores têm um papel estratégico e decisivo na inserção da educação ambiental no cotidiano escolar, qualificando os alunos para um posicionamento crítico face à crise socioambiental, tendo como horizonte a transformação de hábitos e práticas sociais e a formação de uma cidadania ambiental que os mobilize para a questão da sustentabilidade no seu significado mais abrangente.

\section{Palavras-chave}

Educação ambiental - Sociedade de risco - Desenvolvimento sustentável - Interdisciplinaridade. 


\title{
Environmental Education: the challenge of constructing a critical, complex and reflective thinking
}

Pedro Roberto Jacobi

Universidade de São Paulo

\begin{abstract}
The proliferation of risks, particularly of those of severe environmental and technological consequences, is a key element to understand the features, limitations and transformations of our modernity. The complexity of this process is more and more clear in a society not only increasingly threatened but also increasingly affected by socio-environmental risks and harms. The contemporary risks expose the limits and consequences of social practices, bringing with them a new element: the "reflectiveness". The society, a producer of risks, becomes more and more reflective, which means that it becomes a theme and a problem to itself. The concept of risk assumes a strategic role in understanding the characteristics, limitations, and transformations of the historical project of modernity, and to reorient collective and individual lifestyles. In a context marked by the continual degradation of the environment and of its ecosystem, this involves an array of actors from the educative universe in all its levels, stimulating the involvement of the various systems of knowledge and their formation in an interdisciplinary perspective. Educators play a strategic and decisive role in the insertion of environmental education in school everyday life, preparing their students for a critical attitude before the socioenvironmental crisis, having as their horizon the transformation of social habits and practices, and the constitution of an environmental citizenship that will motivate them to the issue of sustainability in its wider meaning.
\end{abstract}

\section{Keywords}

Environmental education - Risk society - Sustainable development - Interdisciplinarity.

Contact:

Pedro Roberto Jacobi

Rua Cayowaa 1082- apto. 61

05018-001 - São Paulo - SP

e-mail: prjacobi@usp.br 


\section{Pensar a sustentabilidade}

0 conceito de desenvolvimento foi objeto de controvérsias, e, até recentemente, a abordagem era de ver desenvolvimento e crescimento econômico como sinônimos. 0 trabalho de Amartya Sen (2004), prêmio Nobel de Economia em 1998, representa um novo momento para a reflexão sobre desenvolvimento como o processo de ampliação da capacidade de os indivíduos terem opções, fazerem escolhas. Relativizando os fatores materiais e os indicadores econômicos, Sen insiste na ampliação do horizonte social e cultural da vida das pessoas. A base material do processo de desenvolvimento é fundamental, mas deve ser considerada como um meio e não como um fim em si. Além da capacidade produtiva, ao postular a melhoria da qualidade de vida em comum, a confiança das pessoas nos outros e no futuro da sociedade, destaca as possibilidades das pessoas levarem adiante iniciativas e inovações que lhes permitam concretizar seu potencial criativo e contribuir efetivamente para a vida coletiva. Sen resume suas idéias sobre o desenvolvimento como as possibilidades que a cooperação e a solidariedade entre os membros da sociedade trazem ao transformar o crescimento econômico de destruidor das relações sociais em processo de formação de capital social ou em "desenvolvimento como liberdade" (Sen, 2004). Para Sen, a expansão da liberdade é o principal fim e meio do desenvolvimento, e só há desenvolvimento quando os benefícios servem à ampliação das capacidades humanas. Segundo ele, isto requer que sejam superadas

as principais fontes de privação de liberdade: pobreza e tirania, carência de oportunidades econômicas e destituição total e sistemática, negligência dos serviços públicos e intolerância ou interferência de Estados repressivos (Sen apud Veiga, 2005, p. 34).

E como emerge a complexa relação entre desenvolvimento e meio ambiente? A incorpora- ção do marco ecológico nas decisões econômicas e sociopolíticas tem na construção do conceito de desenvolvimento sustentável um referencial que assume visibilidade, e que coloca o desenvolvimento como uma forma de modificação da natureza e que portanto, deve contrapor-se tanto os objetivos de atender às necessidades humanas e de outro lado, seus impactos, e dentre estes, aqueles que afetam a base ecológica. A incorporação do marco ecológico nas decisões econômicas e políticas implica reconhecer que as conseqüências ecológicas do modo como a população utiliza os recursos do planeta estão associadas ao modelo de desenvolvimento. 1sto se explicita segundo Guimarães (2001, p. 51), pela crise que afeta o planeta, "o que configura o esgotamento de um estilo de desenvolvimento ecologicamente predador, socialmente perverso, politicamente injusto, culturalmente alienado e eticamente repulsivo". Apesar dessas premissas básicas terem bastante consenso, o "desenvolvimento sustentável” tem se convertido num conceito plural: não apenas existem diferentes concepções do desenvolvimento em jogo, mas também o que se entende por sustentabilidade.

As tensões entre desenvolvimento e conservação do meio ambiente ainda persistem, e o forte viés economicista é um dos fatores de questionamento do conceito pelas organizações ambientalistas. Há definição de diferentes abordagens que apresentam uma diversidade conceitual, enfatizando, entretanto, as enormes diferenças quanto ao significado para as sociedades do Norte e do Sul.

As transformações no debate "meio ambiente-desenvolvimento" têm início nos anos de 1970, quando assumem visibilidade publicações que pretendem mostrar a finitude no interior do modo de produção capitalista e seus impactos globais. A partir desse período, o conceito de desenvolvimento sustentável surge sob diferentes denominações, buscando-se um consenso e sua institucionalização. 0 objetivo é o de elevar a problemática ambiental a um plano de visibilidade na agenda política internacional e fazer com que a temática penetre e conforme as de- 
cisões sobre políticas em todos os níveis (Nobre e Amazonas, 2002). Os projetos de institucionalização encontram no conceito de desenvolvimento sustentável um meio adequado para a disseminação. Nesse sentido, a Conferência Rio 92 pode ser caracterizada como ponto culminante desse projeto de institucionalização e de um novo arranjo teórico e político do debate em torno da problemática ambiental. A sustentabilidade transforma-se no carro-chefe do paradigma de desenvolvimento dos anos de 1990. A expressão “desenvolvimento sustentável” passou a ser usada com sentidos tão diferentes que se tornou uma palavra que serve a todos, e, portanto, adquire um caráter pervasivo. Passa a ser palavra-chave para agências internacionais de fomento, jargão do planejador de desenvolvimento, o tema de conferências, papers e o slogan de ativistas do desenvolvimento e do meio ambiente (Nobre e Amazonas, 2002). Duas correntes interpretativas se sobressaem ao longo deste processo. Uma primeira - econômica e técnico-científica - que propõe a articulação do crescimento econômico e a preservação ambiental, influenciando mudanças nas abordagens do desenvolvimento econômico, notadamente a partir dos anos de 1970. A segunda, relacionada com a crítica ambientalista ao modo de vida contemporâneo, e que se difunde a partir da Conferência de Estocolmo em 1972, momento no qual a questão ambiental ganha visibilidade pública e se coloca a dimensão do meio ambiente na agenda internacional. Duas posições diametralmente opostas foram assumidas: os que previam a abundância (cornucopians) e os catastrofistas (doomsayers) (Sachs, 2000, p. 50-51). Ambas as posições foram descartadas e surge uma posição intermediária entre o economicismo determinista (prioridade ao crescimento econômico) e o fundamentalismo ecológico (inexorabilidade do crescimento do consumo e esgotamento dos recursos naturais). 0 paradigma do caminho do meio - ecodesenvolvimento ou desenvolvimento sustentável - propunha um desenvolvimento que harmonizasse os objetivos sociais, ambientais e econômicos. A idéia ou enfoque do desenvol- vimento sustentável adquire relevância num curto espaço de tempo, assumindo um caráter diretivo nos debates sobre os rumos do desenvolvimento.

Nas décadas de 1980 e 1990, a crescente confluência das duas vertentes economicista e ambientalista - deveu-se principalmente ao avanço da crise ambiental, por um lado, e ao aprofundamento dos problemas econômicos e sociais para a maioria das nações. Dentre as transformações mundiais nestas duas décadas, aquelas vinculadas à degradação ambiental e à crescente desigualdade entre regiões assumem um lugar de destaque que reforçou a importância de adotar esquemas integradores. Embora ambos os processos fossem concebidos inicialmente de maneira fragmentada, sem vinculações evidentes, hoje se torna mais explícita a sua articulação dentro da compreensão no plano de uma crise que assume dimensões globais. Articulam-se, portanto, de um lado, os impactos da crise econômica dos anos de 1980 e a necessidade de repensar os paradigmas existentes; e, de outro, o alarme dado pelos fenômenos de aquecimento global e a destruição da camada de ozônio, dentre outros problemas (Jacobi, 1997; Guimarães, 2001; Conca et al., 1995).

Assim, o que se observa é que, enquanto se agravavam os problemas sociais e se aprofundava a distância entre os países pobres e os industrializados, emergiram com mais impacto diversas manifestações da crise ambiental, que se relacionam diretamente com os padrões produtivos e de consumo prevalecentes.

Os sinais da crescente conscientização podem ser observados a partir de alguns referenciais que agregam propostas de sustentabilidade ambiental, social e de desenvolvimento à dimensão do discurso, como é o caso dos movimentos sociais em defesa da ecologia; as conferências internacionais promovidas pela ONU, principalmente a partir da Conferência das Nações Unidas sobre o Ambiente Humano, realizada em Estocolmo em 1972, para debater os temas do meio ambiente e do desenvolvimento; os relatórios do Clu- 
be de Roma' ; e, mais ou menos diretamente, os trabalhos de autores pioneiros, de diversos campos, que refletiram sobre as mesmas questões. 0 livro A primavera silenciosa, de Rachel Carson, cientista e ecologista americana, lançado em 1962, apresenta um questionamento, nos Estados Unidos, do modelo agrícola convencional e sua crescente dependência do petróleo como matriz energética. Ao tratar do uso indiscrimina-do de substâncias tóxicas na agricultura, alertava para a crescente perda da qualidade de vida produzida pelo uso indiscriminado e excessivo dos produtos químicos e os efeitos dessa utilização sobre os recursos ambientais (Martell, 1994; Dobson, 1994). A contribuição deste livro ${ }^{2}$ foi em relação à necessidade de a sociedade se preocupar com problemas de conservação de recursos naturais, o que já era objeto de muitos outros trabalhos que, desde o século XIX, inspiraram políticas públicas conservacionistas adotadas pelos Estados Unidos no início do século XX (Mc Cormick, 1992).

Logo após a publicação de $A$ primavera silenciosa, trabalhos como o de Paul Ehrlich, (The Population Bomb, 1966) e o de Garret Hardin (Tragedy of the Commons, 1968), reforçaram a teoria malthusiana, relacionando a degradação ambiental e a dos recursos naturais ao crescimento populacional. Em 1972, com a publicação pelo Clube de Roma do livro Limites do crescimento, os cientistas, liderados por Dennis Meadows, argumentam de forma catastrofista que a sociedade se confrontaria dentro de poucas décadas com os limites do seu crescimento por causa do esgotamento dos recursos naturais. Para alcançar a estabilidade econômica e ecológica propõe-se o congelamento do crescimento da população global e do capital industrial, mostrando a realidade dos recursos limitados e indicando um forte viés para o controle demográfico. Estes trabalhos estão assentados na premissa de que a utilização de recursos naturais finitos é uma variável fundamental do processo econômico e social. A sua leitura é que a finitude no modo de produção de mercadorias só pode significar "catástrofe".

No mesmo ano, a Organização das $\mathrm{Na}$ ções unidas promoveu a Conferência de Esto- colmo, que discute a questão ambiental em âmbito planetário, e inseriu a discussão ambiental na agenda internacional. Nesta conferência delineiam-se os principais elementos que, conforme Moll (1991), nos levam “da escassez à sustentabilidade".

Em 1973, utiliza-se pela primeira vez o conceito de ecodesenvolvimento, para caracterizar uma concepção alternativa de desenvolvimento, cujos princípios posteriormente viriam a se integrar à chamada Comissão Brundtland ${ }^{3}$. Tinham como pressuposto a existência de cinco dimensões do ecodesenvolvimento, a saber: 1) a sustentabilidade social, 2) a sustentabilidade econômica, 3) a sustentabilidade ecológica, 4) a sustentabilidade espacial e 5) a sustentabilidade cultural. Estes princípios se articulam com teorias de autodeterminação defendidas pelos países não alinhados desde a década dos anos de 1960 (Sachs, 1986; Guzman, 1997; Jacobi, 1997). Segundo esse conceito,

trata-se de estabelecer que o bem-estar aumenta quando melhora o padrão de vida de um ou mais indivíduos sem que decaia o padrão de vida de outro indivíduo e sem que diminua o estoque de capital natural ou o produzido pelo homem. (Nobre; Amazonas, 2002, p. 35)

O conceito de desenvolvimento sustentável elaborado pela Comissão Brundtland em

1. 0 Clube de Roma foi uma associação livre de cientistas, empresários e políticos de diversos países que se reuniu em Roma, no princípio da década de 1970, para refletir, debater e formular propostas sobre os problemas do sistema global (McCormick, 1992).

2. A autora mostrou como o DDT penetrava na cadeia alimentar e se acumulava nos tecidos gordurosos dos animais, inclusive do homem (chegou a ser detectada a presença de DDT até no leite humano!), com o risco de causar câncer e doenças genéticas. A grande polêmica movida pelo instigante e provocativo livro é que não só ele expunha os perigos do DDT, mas questionava de forma eloqüente a confiança cega da humanidade no progresso tecnológico. Dessa forma, o livro ajudou a abrir espaço para o movimento ambientalista que começava a emergir.

3. Este relatório é o resultado do trabalho da comissão da ONU World Comission on Environment and Development presidida por Gro Harlem Brundtlandt, então primeira-ministra da Noruega, foi organizada pela ONU, em 1983, para estudar a relação entre o desenvolvimento e o meio ambiente e criar uma nova perspectiva para abordar essas questões. 0 Relatório "Nosso Futuro Comum", produzido pela Comissão, veio a público em 1987 (McCormick, 1992). 
1987, ao projetar o termo “desenvolvimento sustentável” o faz, de acordo com Hobsbawn (1995), "convenientemente sem sentido", baseado num conjunto vago de análises e recomendações e, segundo Brookfield (1988), "intencionalmente um documento político, mais do que um tratado científico sobre os problemas do mundo". Daí as críticas dos mais variados matizes que recebeu o relatório, mesmo por parte daqueles que enfatizavam a importância da iniciativa. Para Lélé (1991, p. 613), “o movimento Desenvolvimento Sustentável não foi capaz de desenvolver um conjunto de conceitos, critérios e políticas coerentes ou consistentes tanto do ponto de vista interno como o da realidade social e física".

Os resultados ao início do século $\mathrm{XX1}$, estão muito aquém das expectativas e decorrem da complexidade de estabelecer e pactuar limites de emissões e proteção de biodiversidade, notadamente pelos países mais desenvolvidos.

Apesar das críticas a que tem sido sujeita, a noção de "sustentabilidade" pode se tornar quase universalmente aceita porque reuniu sob si posições teóricas e políticas contraditórias e até mesmo opostas (Nobre; Amazonas, 2002, p. 8). Trata-se de delimitar um campo bastante amplo em que se dá a luta política sobre o seu significado, sendo que a institucionalização da noção de desenvolvimento sustentável sempre esteve permeada por diferentes interpretações, além de servir como instrumento de ancoragem da política ambiental internacional, por meio das agências das Nações Unidas.

Num sentido abrangente, a noção de desenvolvimento sustentável remete à necessária redefinição das relações entre sociedade humana e natureza, e, portanto, a uma mudança substancial do próprio processo civilizatório. Entretanto, a falta de especificidade e as pretensões totalizadoras têm tornado o conceito de desenvolvimento sustentável difícil de ser classificado em modelos concretos, operacionais e analiticamente precisos. Por isso, ainda é possível afirmar que não se constitui num paradigma no sentido clássico do conceito, mas numa orientação ou enfoque, ou ainda numa perspectiva que abrange princípios normativos (Jacobi, 1997; Ruscheinsky, 2004; Guimarães, 2001).

Assim, a noção de sustentabilidade implica a prevalência da premissa de que é preciso determinar uma limitação definida nas possibilidades de crescimento e um conjunto de iniciativas que levem em conta a existência de interlocutores e participantes sociais relevantes e ativos por meio de práticas educativas e de um processo de diálogo informado, o que reforça um sentimento de co-responsabilização e de constituição de valores éticos (Noorgard, 1997; Daly, 1997; Goulet, 1997; Sheng, 1997; Floriani, 2003; Boff, 1999, 2002). Redclift, observa de forma arguta e questionadora que

as ligações entre o meio ambiente, a justiça social e a governabilidade têm se tornado crescentemente vagas em alguns discursos de sustentabilidade, e que as relações estruturais entre o poder, a consciência e o meio ambiente têm sido gradualmente obscurecidas. (2003, p. 48)

Os obstáculos são imensos, na medida em que existe uma restrita consciência na sociedade a respeito das implicações e impactos destrutivos do modelo de desenvolvimento em curso. Também devem ser destacadas as diferenças sociais e as desigualdades econômicas e as enormes assimetrias entre os países do Norte e do Sul.

Os anos de 1990 marcam mudanças significativas no debate internacional sobre os problemas ambientais. A Conferência das Nações Unidas sobre o Meio Ambiente e o Desenvolvimento - Rio 92 - constitui-se um momento importante para a institucionalização da problemática ambiental, sendo que os temas da sustentabilidade e do desenvolvimento sustentável foram adotados como referenciais que presidiram todo o processo de debates, declarações e documentos formulados. Apesar de o objetivo ter sido a institucionalização da problemática ambiental, os resultados da Conferência foram 
aquém dos pretendidos pelos organismos proponentes, e a discussão ambiental sofreu "uma refração em que, de um lado, se consagra a separação entre negociações em torno de acordos ambientais globais e aquelas referentes à implementação de projetos de desenvolvimento sustentável de âmbito nacional, notadamente a Agenda 21" (Nobre e Amazonas, 2002, p. 68). A noção de desenvolvimento sustentável perde gradualmente o seu caráter totalizante que o marcou desde os primeiros momentos, e se torna "deliberadamente vaga e inerentemente contraditória” (0’ Riordan, 1993, p. 7).

0 debate internacional, segundo Guimarães (2001, p. 17), que teve início em Estocolmo e se ampliou na Rio-92, transcende a perspectiva tecnocrática no tratamento da crise ambiental, a ilusão ingênua de que os avanços do conhecimento científico seriam suficientes para permitir a emergência de um estilo sustentável de desenvolvimento.

Uma outra iniciativa marcante e que teve ampla repercussão foi a Carta da Terra, resultado da mobilização e articulação da sociedade civil que se inicia a partir da publicação de Nosso futuro comum, em 1987, e cuja primeira versão foi discutida na Eco 92, durante o Fórum Global de ONGs. Apenas em março de 2000, e após amplos processos públicos de debates em quarenta e seis países durante oito anos, foi ratificada pela Unesco. Trata-se de uma declaração de princípios globais que orienta as ações individuais e coletivas rumo ao desenvolvimento sustentável e sugere parâmetros éticos globais. Boff (2002, p. 54-55) destaca três pontos relevantes: resgate de valores da solidariedade, da inclusão e da reverência; superação do conceito fechado de desenvolvimento sustentável; e ética do cuidado.

As expectativas geradas com os avanços na Rio-92 se reduzem significativamente antes e após a mais recente Cúpula do Mundial sobre Meio Ambiente e Desenvolvimento Sustentável - Rio + 10, realizada em 2002 em Johanesburgo, onde não se concretizaram os objetivos de aprofundar o debate em torno do desenvolvimento sustentável e praticamente não foram acordados novos passos nem no plano teórico, nem nas medidas práticas.

Apesar dos avanços ocorridos em vários setores, os princípios de proteção ambiental e de "desenvolvimento sustentável" continuam a ser considerados um entrave para o crescimento econômico, e os resultados estão à mostra: perda de biodiversidade, degradação da qualidade ambiental nas grandes cidades dos países em desenvolvimento, redução dos recursos não renováveis.

0 quadro atual, claramente demonstrado por estudos científicos, indica que os ecossistemas continuam sentindo o impacto de padrões insustentáveis de produção e de urbanização. Além disso, durante a última década, muitos países aumentaram sua vulnerabilidade a uma série mais intensa e freqüente de fenômenos que tornam mais frágeis os sistemas ecológicos e sociais, provocando insegurança ambiental, econômica e social, minando a sustentabilidade e gerando incertezas em relação ao futuro. Prevalece ainda a ideologia do progresso, que rejeita ou minimiza as questões ambientais, seja no discurso ou na prática.

Apesar deste quadro de problemas, não devem ser desconsideradas as "boas práticas de sustentabilidade" em escala local, que dependem da capacidade empreendedora de atores locais ou regionais.

Cabe ressaltar que a proliferação de posições sobre a sustentabilidade é um sintoma positivo de dinamismo, já que os debates atuais eram impensáveis há alguns anos. Isto mostra que as mudanças são possíveis, e que a questão da sustentabilidade tem muitas leituras, algumas contraditórias e outras convergentes, apesar de apropriadas de forma diferenciada pelos grupos e pessoas que atuam numa perspectiva de propor uma sustentabilidade articulada a novas realidades materiais e novas posições epistemológicas.

\section{Sociedade de risco, reflexividade e complexidade}

A multiplicação dos riscos, em especial os ambientais e tecnológicos de graves conseqüências, é elemento chave para entender as 
características, os limites e as transformações da modernidade. Os riscos contemporâneos (Beck, 1997, p. 16-17) explicitam os limites e as conseqüências das práticas sociais, trazendo consigo um novo elemento, a "reflexividade". A sociedade, produtora de riscos, torna-se cada vez mais reflexiva, o que significa dizer que ela se torna um tema e um problema para si própria. A sociedade torna-se cada vez mais autocrítica, e, ao mesmo tempo em que a humanidade põe a si em perigo, reconhece os riscos que produz e reage diante disso. A sociedade global "reflexiva" se vê obrigada a autoconfrontar-se com aquilo que criou, seja de positivo ou de negativo. 0 conceito de risco passa a ocupar um papel estratégico para entender as caracteristicas, os limites e as transformações do projeto histórico da modernidade (Beck, 1997, p. 16-17).

Os grandes acidentes envolvendo usinas nucleares e contaminações tóxicas de intensas proporções, como os casos de ThreeMile Island (1979), Love Canal (1979), Bhopal (1984) e Chernobyl (1986), além de outros de menor porte, mas com impactos locais significativos, aumentam o debate público e científico sobre a questão dos riscos nas sociedades contemporâneas. Os riscos estão diretamente relacionados com a modernidade e os ainda imprevisíveis efeitos da globalização, como uma radicalização dos princípios da modernidade (Beck, 1997, p. 18). 0 desenvolvimento do sistema industrial criou um mundo pautado pela incerteza e a "modernização reflexiva" da alta modernidade. Na sociedade de risco, o impacto da globalização, as transformações do cotidiano e o surgimento da sociedade pós-tradicional se caracterizam pela sua instantaneidade, embora contraditória, que inter-relaciona o global e o local e configura novas formas de desigualdades. 0 progresso gerado pelo desenvolvimento da ciência e da tecnologia passa a ser considerado como fonte potencial de autodestruição da sociedade industrial, a partir do qual se produzem, por sua vez, novos riscos, de caráter global - afetando o planeta, atravessando fronteiras nacionais e de classes (Guivant, 1998, p. 18).
A nova realidade pós-tradicional da modernidade radicalizada gera crescente incerteza, mutabilidade e reflexividade. 0 progresso pode se transformar em autodestruição, na qual um tipo de modernização destrói o outro e o modifica. Coloca-se, portanto, a possibilidade de se reinventar, ou repensar, a civilização industrial, ao se sugerir uma (auto)destruição criativa (Beck, 1997, p. 12-13). Observa-se uma transformação da sociedade industrial, originando a sociedade de risco. Nesse sentido, para Beck (1997, p. 28), a "subpolítica"4 resulta de um renascimento não institucional do político, paralelo ao vazio político das instituições. Beck assim explicita a "subpolítica" como disseminação de um engajamento político e de um ativismo derivado da política que migrou do parlamento para grupos de pressão unidirecionados na sociedade (ecologismo, movimento de mulheres, movimento homossexual etc.).

É cada vez mais notória a complexidade desse processo de transformação de uma sociedade crescentemente não só ameaçada, mas diretamente afetada por riscos e agravos socioambientais. Num contexto marcado pela degradação permanente do meio ambiente e do seu ecossistema, a problemática envolve um conjunto de atores do universo educativo em todos os níveis, potencializando o engajamento dos diversos sistemas de conhecimento, a capacitação de profissionais e a comunidade universitária numa perspectiva interdisciplinar.

Vive-se, no início do século XXl, uma emergência que, mais que ecológica, é uma crise do estilo de pensamento, dos imaginários sociais, dos pressupostos epistemológicos e do conhecimento que sustentaram a modernidade. Uma crise do ser no mundo que se manifesta em toda sua plenitude: nos espaços internos do sujeito, nas condutas sociais autodestrutivas; e nos espaços externos, na degradação da natureza e da qualidade de vida das pessoas.

A essência da crise ambiental é a incerteza, e isto terá maior ou menor impacto de acor-

4. Subpolítica para Beck (1997, p. 35) significa "moldar a sociedade de baixo para cima". 
do com a forma como a sociedade, segundo Beck (1997, p. 17) "levanta a questão da autolimitação do desenvolvimento, assim como da tarefa de redeterminar os padrões (de responsabilidade, segurança, controle, limitação do dano e distribuição das conseqüências do dano) atingidos aquele momento, levando em conta as ameaças potenciais".

0 tema da sustentabilidade confronta-se com o paradigma da "sociedade de risco". Isto implica a necessidade de se multiplicarem as práticas sociais baseadas no fortalecimento do direito ao acesso à informação e à educação em uma perspectiva integradora.

Observa-se a necessidade de se incrementar os meios e a acessibilidade à informação, bem como o papel indutivo do poder público nos conteúdos educacionais e informativos de sua oferta, como caminhos possíveis para alterar o quadro atual de degradação socioambiental. Trata-se de promover o crescimento de uma sensibilidade maior das pessoas face aos problemas ambientais, como uma forma de fortalecer sua coresponsabilidade na fiscalização e no controle da degradação ambiental (Jacobi, 2003).

Nessa direção, a problemática ambiental constitui um tema muito propício para aprofundar a reflexão e a prática em torno do restrito impacto das ações de resistência e de expressão das demandas da população das áreas mais afetadas pelos constantes e crescentes agravos ambientais. Mas representa também a possibilidade de abertura de estimulantes espaços para implementar alternativas diversificadas de participação social, notadamente a garantia do acesso à informação e a consolidação de canais abertos.

A postura de dependência e de não responsabilidade da população decorre principalmente da desinformação, da falta de consciência ambiental e de um déficit de práticas comunitárias baseadas na participação e no envolvimento dos cidadãos, que proponham uma nova cultura de direitos baseada na motivação e na co-participação na gestão do meio ambiente, nas suas diversas dinâmicas.
Nesse contexto, as práticas educativas devem apontar para propostas pedagógicas centradas na mudança de hábitos, atitudes e práticas sociais, desenvolvimento de competências, capacidade de avaliação e participação dos educandos. Isto desafia a sociedade a elaborar novas epistemologias que possibilitem o que Morin (2003) denomina de "uma reforma do pensamento" (apud Floriani, 2003, p. 116). No novo contexto do conhecimento do qual emergem as novas epistemologias socioambientais, plurais e diferenciadas, Capra (2003) representa a busca da unificação do conhecimento com a natureza e a sociedade, Morin (2003) pensa a complexidade como referencial principal para explicar os novos sentidos do mundo, e Leff (2001), uma nova racionalidade ambiental, capaz de subverter a ordem imperante entre as lógicas de vida e o destino das sociedades (Floriani; Knechtel, 2003, p. 16). Assim, o conceito de ambiente situa-se numa categoria não apenas biológica, mas que constitui "uma racionalidade social, configurada por comportamentos, valores e saberes, como também por novos potenciais produtivos" (Leff, 2001, p. 224). Uma mudança paradigmática implica uma mudança de percepção e de valores, e isto deve orientar de maneira decisiva para formar as gerações atuais não somente para aceitar a incerteza e o futuro, mas para gerar um pensamento complexo e aberto às indeterminações, às mudanças, à diversidade, à possibilidade de construir e reconstruir num processo contínuo de novas leituras e interpretações, configurando novas possibilidades de ação (Morin, 2001; Capra, 2003; Leff, 2003).

Embora os primeiros registros da utilização do termo "educação ambiental" datassem de 1948 num encontro da União Internacional para a Conservação da Natureza (UICN) em Paris, os rumos da educação ambiental são definidos a partir da Conferência de Estocolmo, na qual se recomenda o estabelecimento de programas internacionais. Em 1975, lança-se em Belgrado o Programa Internacional de Educação Ambiental, no qual são definidos os princípios e as orientações para o futuro ${ }^{5}$. Desde 
então, três momentos marcam a trajetória do processo de institucionalização e pactuação da necessidade da inserção da educação ambiental no nível planetário.

Cinco anos após Estocolmo, em 1977, acontece em Tbilisi, na Geórgia, a Conferência Intergovernamental sobre Educação Ambiental. lsto inicia um processo global orientado para criar as condições para formar uma nova consciência sobre o valor da natureza e para reorientar a produção de conhecimento baseada nos métodos da interdisciplinariedade e os princípios da complexidade. Esta

aponta nesse momento para a Educação Ambiental como um meio educativo pelo qual se podem compreender de modo articulado as dimensões ambiental e social, problematizar a realidade e buscar as raizes da crise civilizatória. (Loureiro, 2004, p. 71)

Durante a Rio-92 foi redigido o Tratado de Educação Ambiental para Sociedades Sustentáveis e Responsabilidade Global, que estabelece dezesseis princípios fundamentais da educação para as sociedades sustentáveis, enfatizando a necessidade de um pensamento crítico, de um fazer coletivo e solidário, da interdisciplinariedade, da multiplicidade e diversidade. Estabelece igualmente um conjunto de compromissos coletivos para a sociedade civil planetária.

Em Tessalonika, no ano de 1997, o documento resultante da Conferência Internacional sobre Meio Ambiente e Sociedade: Educação e Consciência Pública para a Sustentabilidade reforça os temas colocados na Eco-92, e chama a atenção para a necessidade de se articularem ações de educação ambiental baseadas nos conceitos de ética e sustentabilidade, identidade cultural e diversidade, mobilização e participação, além de práticas interdisciplinares. 0 que os pesquisadores observam é que as recomendações são vagas e sem maiores efeitos práticos, sendo que muitas delas apenas servem para alimentar a lógica de mercado e as políticas liberais.
As iniciativas planetárias para pactuar práticas de educação ambiental explicitam o desafio de construção de uma formulação conceitual que estabeleça uma comunicação entre ciências sociais e exatas. Morin (2003) define que o paradigma da complexidade corresponde à irrupção dos antagonismos no seio dos fenômenos organizados - uma visão complexa do universo por meio de certos princípios de inteligibilidade unidos uns aos outros.

Para Morin (2003), o pensamento complexo - distinção, conjunção e implicação - se contrapõe às operações lógicas que caracterizam o pensamento simplificador - disjunção e redução que "tem gerado a inteligência cega, que destrói os conjuntos e as totalidades, isola e separa os objetos de seus ambientes”. Na argumentação sobre o pensamento complexo, enfatiza três princípios norteadores: o dialógico - mantendo a dualidade no seio da unidade; o da recursividade organizacional - uma sociedade que, ao produzirse, retroage sobre os indivíduos; e o hologramático - a parte está no todo e o todo está na parte. E assim reconhece a complexidade que permeia os sistemas/organizações (Floriani, 2003, p. 114). Esta reforma do pensamento permite a integração do contexto e do complexo, compreendendo as inter-relações, multidimensionalidades, dinâmicas que respeitem e assimilem a unidade e a diversidade, baseadas em princípios éticos e no reconhecimento das diferenças (Morin, 2002; Morin et al., 2003). 0 paradigma da complexidade coloca o desafio do diálogo entre certeza e incerteza, propiciando que os indivíduos vivenciem uma realidade marcada pela indeterminação, a interdependência e a causalidade entre os diferentes processos. Entretanto, isto não deve se transformar numa camisa de força conceitual e metodo-lógica, mas numa articulação entre os processos subjetivos e objetivos que estão presentes na produção de conhecimento e de sentidos.

Refletir sobre a complexidade ambiental abre um estimulante espaço para compreender a

5. Nessa ocasião redige-se a Carta de Belgrado, assinada pelos representantes de 65 países. 
gestação de novos atores sociais que se mobilizam para a apropriação da natureza, para um processo educativo articulado e compromissado com a sustentabilidade e a participação, apoiado numa lógica que privilegia o diálogo e a interdependência de diferentes áreas de saber. Mas também questiona valores e premissas que norteiam as práticas sociais prevalecentes, isto implicando uma mudança na forma de pensar, uma transformação no conhecimento e nas práticas educativas.

É cada vez mais notória a complexidade do processo de transformação de um planeta não apenas cada vez mais ameaçado, mas também diretamente afetado pelos riscos socioambientais e seus danos.

Floriani (2003, p. 81-132), mostra como Morin e Leff, apontam, cada um ao seu modo, para matrizes alternativas de integração do conhecimento que superem o paradigma dualista, e enfatizam a complexidade e a interdisciplinaridade como elemento constitutivo de um novo pensar sobre as relações sociedade-natureza. A premissa que norteia o paradigma proposto é o diálogo de saberes que permita construir espaços de fronteiras (Sauvé, 1999, p. 19-20) que nos confrontem com os diversos reducionismos $\mathrm{e}$ pragmatismos conceituais.

A necessidade de abordar o tema da complexidade ambiental decorre da percepção quanto ao incipiente processo de reflexão sobre as práticas existentes e as múltiplas possibilidades que estão colocadas para, ao pensar a realidade de modo complexo, defini-la como uma nova racionalidade e um espaço no qual se articulam natureza, técnica e cultura.

\section{Educação Ambiental: desafios e construção de práticas de cidadania ambiental}

As premissas teóricas em torno do diálogo de saberes entre educação e meio ambiente, nas suas múltiplas dimensões e como campo teórico em construção, têm sido apropriadas de formas diferentes pelos educadores ambientais, que buscam uma nova transversalidade de sabe- res, um novo modo de pensar, pesquisar e elaborar conhecimento, que possibilite integrar teoria e prática.

Deve-se, entretanto, ressaltar que as práticas educacionais inseridas na interface dos problemas socioambientais devem ser compreendidas como parte do macrossistema social, subordinando-se ao contexto de desenvolvimento existente, que condiciona sua direção pedagógica e política. Quando nos referimos à educação ambiental, a situamos num contexto mais amplo, o da educação para a cidadania, configurando-se como elemento determinante para a consolidação de sujeitos cidadãos (Jacobi, 2000). 0 principal eixo de atuação deve buscar, acima de tudo, a solidariedade, a igualdade e o respeito à diferença por meio de formas democráticas de atuação baseadas em práticas interativas e dialógicas. Entende-se que a educação para a cidadania trata não só da capacidade do indivíduo de exercer os seus direitos nas escolhas e nas decisões políticas, como ainda de assegurar a sua total dignidade nas estruturas sociais. Desse modo, o exercício da cidadania implica autonomia e liberdade responsável, participação na esfera política democrática e na vida social. Os cidadãos desenvolvem ações de integração social, conservação do ambiente, justiça social, solidariedade, segurança e tolerância, as quais constituem preocupações da sociedade atual. Pretende-se, assim, sensibilizar alunos e professores para uma participação mais consciente no contexto da sociedade, questionando comportamentos, atitudes e valores, além de propor novas práticas.

Assim, nossa argumentação vai no sentido de reforçar que as práticas educativas articuladas com a problemática ambiental não devem ser vistas como um adjetivo, mas como parte componente de um processo educativo que reforce um pensar da educação orientado para refletir a educação ambiental num contexto de crise ambiental, de crescente insegurança e incerteza face aos riscos produzidos pela sociedade global, o que, em síntese, pode ser resumido como uma crise civilizatória de um modelo 
de sociedade. Nesse sentido, a formulação de Leff $(2001$, p. 256) nos permite enfatizar que este processo educativo deve ser capaz de formar um pensamento crítico, criativo e sintonizado com a necessidade de propor respostas para o futuro, capaz de analisar as complexas relações entre os processos naturais e sociais e de atuar no ambiente em uma perspectiva global, respeitando as diversidades socioculturais. 0 objetivo é o de propiciar novas atitudes e comportamentos face ao consumo na nossa sociedade e de estimular a mudança de valores individuais e coletivos (Jacobi, 1997). lsto requer um pensamento crítico da educação ambiental, e, portanto, a definição de um posicionamento ético-político, "situando o ambiente conceitual e político onde a educação ambiental pode buscar sua fundamentação enquanto projeto educativo que pretende transformar a sociedade" (Carvalho, 2004, p. 18)

A partir das sinteses realizadas por Lima (2002, p. 109-141) e Loureiro (2004) podem observar-se dois eixos para o discurso da educação ambiental: um conservador e outro emancipatório, com suas diferentes leituras. A abordagem conservadora, pautada por uma visão reformista, propõe respostas instrumentais. Observa-se, de fato, que o modus operandi que predomina é o das ações pontuais, descontextualizadas dos temas geradores, freqüentemente descoladas de uma proposta pedagógica, sem questionar o padrão civilizatório, apenas realimentando uma visão simplista e reducionista.

A abordagem emancipatória, que tem como referenciais no campo da educação o pensamento crítico (Paulo Freire, Snyder e Giroux) ${ }^{6}$ e, no que se refere ao meio ambiente, autores como Capra, Morin, Leff, e Boff, dentre outros, propõe uma educação baseada em práticas, orientações e conteúdos que transcendem a preservação ambiental. Parafraseando Morin,

na educação ambiental crítica, o conhecimento para ser pertinente não deriva de saberes desunidos e compartimentalizados, mas da apreensão da realidade a partir de algu- mas categorias conceituais indissociáveis ao processo pedagógico. (2002, p. 36)

Para a vertente crítica, a educação ambiental precisa construir um instrumental que promova uma atitude crítica, uma compreensão complexa e a politização da problemática ambiental, a participação dos sujeitos, o que explicita uma ênfase em práticas sociais menos rígidas, centradas na cooperação entre os atores.

$\mathrm{Na}$ ótica da modernização reflexiva, a educação ambiental tem de enfrentar a fragmentação do conhecimento e desenvolver uma abordagem crítica e política, mas reflexiva.

Portanto, a dimensão ambiental representa a possibilidade de lidar com conexões entre diferentes dimensões humanas, possibilitando entrelaçamentos e trânsitos entre múltiplos saberes. Atualmente, o desafio de fortalecer uma educação para a cidadania ambiental convergente e multi-referencial se coloca como prioridade para viabilizar uma prática educativa que articule de forma incisiva a necessidade de se enfrentar concomitantemente a crise ambiental e os problemas sociais. Assim, o entendimento sobre os problemas ambientais se dá por meio da visão do meio ambiente como um campo de conhecimento e significados socialmente construídos, que é perpassado pela diversidade cultural e ideológica e pelos conflitos de interesse.

Os educadores devem estar cada vez mais preparados para reelaborar as informações que recebem, e, dentre elas, as ambientais, para poder transmitir e decodificar para os alunos a expressão dos significados em torno do meio ambiente e da ecologia nas suas múltiplas determinações e intersecções. A ênfase deve ser a capacitação para perceber as relações entre as áreas e como um todo, enfatizando uma formação local/global, buscando marcar a necessidade de enfrentar a lógica da exclusão e das desigualdades. Nesse contexto, a administração

6. Para estes, a escola apresenta rupturas por meio das quais é possível exercer práticas críticas e trabalhar a resistência à reprodução e à dominação ideológicas. (Loureiro, 2004, p. 121) 
dos riscos socioambientais coloca cada vez mais a necessidade de ampliar o envolvimento público através de iniciativas que possibilitem um aumento do nível de preocupação dos educadores com o meio ambiente, garantindo a informação e a consolidação institucional de canais abertos para a participação numa perspectiva pluralista.

A educação ambiental assume, assim, de maneira crescente, a forma de um processo intelectual ativo, enquanto aprendizado social, baseado no diálogo e interação em constante processo de recriação e reinterpretação de informações, conceitos e significados, que se originam do aprendizado em sala de aula ou da experiência pessoal do aluno. A abordagem do meio ambiente na escola passa a ter um papel articulador dos conhecimentos nas diversas disciplinas, num contexto no qual os conteúdos são ressignificados. Ao interferir no processo de aprendizagem e nas percepções e representações sobre a relação entre indivíduos e ambiente nas condutas cotidianas que afetam a qualidade de vida, a educação ambiental promove os instrumentos para a construção de uma visão crítica, reforçando práticas que explicitam a necessidade de problematizar e agir em relação aos problemas socioambientais, tendo como horizonte, a partir de uma compreensão dos conflitos, partilhar de uma ética preocupada com a justiça ambiental.

A ótica inovadora refere-se à forma como se apreende o objeto de conhecimento e à dinâmica que se estabelece com os atores sociais que propõem uma nova forma de integração e articulação do conhecimento ambiental. A prática educativa deve estar norteada pela formação de um indivíduo que supere o que Guimarães (2004, p. 30) denomina de "armadilhas paradigmáticas"7, contribuindo para o exercício de uma cidadania ativa visando a mudar o atual quadro de crise socioambiental.

Esta abordagem busca superar o reducionismo e estimula um pensar e fazer sobre o meio ambiente diretamente vinculado ao diálogo entre saberes, à participação, aos valores éticos como valores fundamentais para fortale- cer a complexa interação entre sociedade e natureza. Nesse sentido, o papel dos professores é essencial para impulsionar as transformações de uma educação que assume um compromisso com o desenvolvimento sustentável e também com as futuras gerações. Autores como Carvalho (2003); Leff (2003); Sauvé (1999) e Gaudiano (2000) mostram como um discurso ambiental dissociado das condições sócio-históricas pode ser alienante e levar a posições politicamente conservadoras, na medida em que mobiliza o que Carvalho (2003, p. 116-117) denomina de um consenso dissimulado, em virtude da generalização e do esvaziamento do termo desenvolvimento sustentável, das diferenças ideológicas e os conflitos de interesses que se confrontam no ideário ambiental.

Isto nos leva à reflexão sobre a necessidade da formação do profissional reflexivo para desenvolver práticas que articulem a educação e o meio ambiente numa perspectiva crítica, que abra perspectivas para uma atuação ecológica sustentada por princípios de criatividade e capacidade de formular e desenvolver práticas emancipatórias norteadas pelo empoderamento e pela justiça ambiental e social.

A inserção da educação ambiental numa perspectiva crítica ocorre na medida em que o professor assume uma postura reflexiva. Isto potencializa entender a educação ambiental como uma prática político-pedagógica, representando a possibilidade de motivar e sensibilizar as pessoas para transformar as diversas formas de participação em potenciais fatores de dinamização da sociedade e de ampliação da responsabilidade socioambiental. Esta se concretizará principalmente pela presença crescente de uma pluralidade de atores que, por meio da ativação do seu potencial de participação, terão cada vez mais condições de intervir consistentemente e sem tutela nos processos decisórios de interesse público, legitimando e consolidando

7. Trata-se de reprodução nas ações educativas dos paradigmas constituintes da sociedade moderna atrelada a uma racionalidade dominante que busca ser inquestionável. 
propostas de gestão baseadas na garantia do acesso à informação e na consolidação de canais abertos para a participação.

As experiências interdisciplinares são recentes e incipientes, até mesmo em nível de pósgraduação. 0 que prevalece são práticas multidisciplinares e, segundo Tristão (2002, p. 175), "como as disciplinas de geografia e biologia têm uma afinidade de conteúdos em relação à dimensão ambiental, a inserção da educação ambiental ocorre por meio de um exercício multidisciplinar, às vezes até de uma cooperação entre os conteúdos dessas disciplinas".

Tristão (2002, p. 173-181) observa que existem quatro desafios da educação ambiental que, entrelaçados, estão associados ao papel do educador na contemporaneidade. 0 primeiro desafio é o de "enfrentar a multiplicidade de visões”, e isto implica a preparação do educador para fazer as conexões (Capra, 2003, p. 9499) e articular os processos cognitivos com os contextos da vida. Assim, entender a complexidade ambiental, não como "moda" ou "reificação" ou "utilização indiscriminada", mas como construção de sentidos fundamental para identificar interpretações e generalizações feitas em nome do meio ambiente e da ecologia. 0 segundo desafio é o de "superar a visão do especialista”, e para tanto o caminho é a ruptura com as práticas disciplinares. 0 terceiro desafio é "superar a pedagogia das certezas", e isto converge com as premissas que norteiam a formação do "professor reflexivo", o que implica compreender a modernidade, os "riscos produzidos" (Giddens, 1991, p. 140) e seu potencial de reprodução, além de desenvolver no espaço pedagógico uma sensibilização em torno da complexidade da sociedade contemporânea e suas múltiplas causalidades. 0 quarto desafio é superar a lógica da exclusão, que soma ao desafio da sustentabilidade a necessidade da superação das desigualdades sociais.

0 momento atual é o de consolidar práticas pedagógicas que estimulem a interdisciplinaridade, na sua diversidade. Recorremos a Stengers para expressar nosso ponto de vista:
A noção de complexidade é perigosa do ponto de vista da política dos saberes. É, com efeito, uma noção que está na moda, e essa moda contém uma armadilha. A armadilha dos grandes discursos sobre a complexidade. (1990, p. 148)

0 desafio da interdisciplinariedade é enfrentado como um processo de conhecimento que busca estabelecer cortes transversais na compreensão e explicação do contexto de ensino e pesquisa, buscando a interação entre as disciplinas e superando a compartimentalização científica provocada pela excessiva especialização.

Como combinação de várias áreas de conhecimento, a interdisciplinariedade pressupõe o desenvolvimento de metodologias interativas, configurando a abrangência de enfoques e contemplando uma nova articulação das conexões entre as ciências naturais, sociais e exatas. Cabe ressaltar que o contexto epistemológico da educação ambiental permite um conhecimento aberto, processual e reflexivo, a partir de uma articulação complexa e multirreferencial. Nesse sentido, o conhecimento transdisciplinar se configura como um horizonte mais ousado de conhecimento. Para Morin (2000, p. 37), a transdisciplinaridade estaria mais próxima do exercício do pensamento complexo, pelo fato de ter como pressuposto a transmigração e diálogo de conceitos através de diversas disciplinas.

A preocupação em consolidar uma dinâmica de ensino e pesquisa a partir de uma perspectiva interdisciplinar enfatiza a importância dos processos sociais que determinam as formas de apropriação da natureza e suas transformações, por meio da participação social na gestão dos recursos ambientais, levando em conta a dimensão evolutiva no sentido mais amplo e incluindo as conexões entre as diversidades biológica e cultural, assim como as práticas dos diversos atores sociais e o impacto da sua relação com o meio ambiente.

Dessa forma, a ênfase na interdisciplinariedade na análise das questões ambientais deve-se à constatação de que os problemas que 
afetam e mantêm a vida no nosso planeta são de natureza global e que a compreensão de suas causas não pode restringir-se apenas aos fatores estritamente biológicos, revelando dimensões políticas, econômicas, institucionais, sociais e culturais.

Porém, não é suficiente reunir diferentes disciplinas para o exercício interdisciplinar. A educação ambiental deve apoiar-se em trocas sistemáticas e no confronto de saberes disciplinares que incluam não apenas uma problemática nas interfaces entre as diversas ciências naturais e sociais e isto só se concretizará a partir de uma ação orgânica das diversas disciplinas, superando a visão multidisciplinar.

Posto que os problemas ambientais transcendem as diferentes disciplinas, tanto o aprofundamento disciplinar quanto a ampliação do conhecimento entre as disciplinas são elementos fundamentais, porém de grande complexidade quanto à sua implementação. Considerando como ponto de partida uma realidade socioambiental complexa, esse processo exige, cada vez mais, a internalização de um saber ambiental emergente num conjunto de disciplinas, visando a construir um campo de conhecimento capaz de captar as multicausalidades e as relações de interdependência dos processos de ordem natural e social que determinam as estruturas e mudanças socioambientais.

Concluímos afirmando que o desafio político-ético da educação ambiental, apoiado no potencial transformador das relações sociais, encontra-se estreitamente vinculado ao processo de fortalecimento da democracia e da construção de uma cidadania ambiental. Nesse sentido, o papel dos educadores e professores é essencial para impulsionar as transformações de uma educação que assume um compromisso com a formação de uma visão crítica, de valo- res e de uma ética para a construção de uma sociedade ambientalmente sustentável.

A necessidade de uma crescente internalização da questão ambiental, um saber ainda em construção, demanda um esforço de fortalecer visões integradoras que, centradas no desenvolvimento, estimulam uma reflexão em torno da diversidade e da construção de sentidos nas relações indivíduos-natureza, nos riscos ambientais globais e locais e nas relações ambiente-desenvolvimento. Nesse contexto, a educação ambiental aponta para a necessidade de elaboração de propostas pedagógicas centradas na conscientização, mudança de atitude e práticas sociais, desenvolvimento de conhecimentos, capacidade de avaliação e participação dos educandos.

A relação entre meio ambiente e educação assume um papel cada vez mais desafiador, demandando a emergência de novos saberes para apreender processos sociais cada vez mais complexos e riscos ambientais que se intensificam. Nas suas múltiplas possibilidades, abre um estimulante espaço para um repensar de práticas sociais e o papel dos educadores na formação de um "sujeito ecológico" (Carvalho, 2004).

A restrita presença do debate ambiental, seja como disciplina, seja como eixo articulador nos currículos dos cursos de formação de professores (MEC, 2000), é um bom indicador do desafio de internalização da educação ambiental nos espaços educativos. Isto coloca a necessidade de uma permanente sensibilização dos professores, educadores e capacitadores como transmissores de um conhecimento necessário para que os alunos adquiram uma base adequada de compreensão dos problemas e riscos socioambientais, do seu impacto no meio ambiente global e local, da interdependência dos problemas e da necessidade de cooperação e diálogo entre disciplinas e saberes. 


\section{Referências bibliográficas}

BECK, U. Risk Society. London: Sage Publications, 1994.

A Reinvenção da Política. In: GIDDENS, A. et al. Modernização Reflexiva. São Paulo: UNESP, 1997.

BOFF, L. Saber cuidar: ética do humano, compaixão pela terra. Petrópolis: Vozes, 1999.

Um ethos para salvar a Terra. In: CAMARG0, A. et al. Meio ambiente Brasil: abanicos e obstáculos pós Rio-92. São Paulo: Estação Liberdade/ ISA, 2002, p. 49-56.

BROOKFIEL, H. Sustainable development and the environment. The Journal of Development Studies. London: Routledge, v. 3/1, 1988.

CAPRA, F. As conexões ocultas. São Paulo: Cultrix, 2003.

CARSON, R. Silent Spring. New York: Houghton and Mifflin, 1994.

CARVALHO, I. A invenção ecológica. Porto Alegre: Editora da UFRGS, 2001.

. Os sentidos do "ambiental": a contribuição da hermenêutica à pedagogia da complexidade. In: LEFF, E. (Org.). A complexidade ambiental. Cortez Editora, São Paulo, 2003.

Educação ambiental crítica: nomes e endereçamentos da educação. In: MMA/ Secretaria Executiva/ Diretoria de Educação Ambiental (Org.). Identidades da educação ambiental brasileira. Brasília: MMA, 2004.

CONCA, K. et al. Green planet blues. Oxford: Westview, 1995.

DALY, H. Políticas para o desenvolvimento sustentável. In: CAVALCANTli, C. (Org.). Meio ambiente, desenvolvimento sustentável e políticas públicas. São Paulo: Cortez Editora, 1997.

DOBSON, A. Green political thought. London: Routledge, 1994.

FLORIANI, D. Conhecimento, meio ambiente e globalização. Curitiba: Juruá, 2003.

FLORIANI, D.; KNECHTEL, M. do R. Educação ambiental, epistemologia e metodologias. Curitiba: Vicentinas, 2003.

GAUDIANO, E. Complejidad en educación ambiental. Tópicos en Educación Ambiental. México: Semarnap, v. 2, n. 4, p. 21-32. 2000.

GIDDENS, A. Conseqüências da modernidade. São Paulo: Unesp, 1991.

GUIMARÃES, M. A formação de educadores ambientais. Campinas: Papirus, 2004.

GUIMARÃES, R. A ética da sustentabilidade e a formulação de políticas de desenvolvimento. In: VIANA, G. et al. (Org.) 0 desafio da sustentabilidade. São Paulo: Fundação Perseu Abramo, 2001.

GUIVANT, J. A trajetória das análises de risco: da periferia ao centro da teoria social. Revista Brasileira de Informação Bibliográfica em Ciências Sociais. Rio de Janeiro: Relume Dumará, 1998.

GOULET, D. Desenvolvimento autêntico: fazendo-o sustentável. In: CAVALCANTI, C. (Org.). Meio ambiente, desenvolvimento sustentável e políticas públicas. São Paulo: Cortez Editora, 1997.

GARCIA, R. Interdisciplinariedad y sistemas complejos. In: LEFF, E. (Coord.). Ciencias y formación ambiental. Barcelona: GEDISA/CIIH-UNAM/ PNUMA, 1994.

GUZMAN, E. Origem, evolução e perspectivas do desenvolvimento sustentável. In: ALMEIDA, J.; NAVARRO, Z. Reconstruindo a agricultura: idéias e ideais na perspectiva do desenvolvimento rural sustentável. Porto Alegre: Editora UFRGS, p. 19-32, 1997. 
HOBSBAWN, E. A era dos extremos. São Paulo: Companhia das Letras, 1995.

JACOBI, P. Meio ambiente urbano e sustentabilidade: alguns elementos para a reflexão. In: CAVALCANTI, C. (Org.). Meio ambiente, desenvolvimento sustentável e políticas públicas. São Paulo: Cortez Editora, 1997.

(Org.) Ciência ambiental: os desafios da interdisciplinariedade. São Paulo: Annablume, 1999.

Políticas sociais e ampliação da cidadania. Rio de Janeiro: FGV Editora, 2000.

Meio ambiente e redes sociais: dimensões intersetoriais e complexidade na articulação das práticas coletivas. Revista de Administração Pública. Rio de Janeiro: Fundação Getúlio Vargas, v. 34, n. 6, p. 131-158, 2000.

Educação ambiental, cidadania e sustentabilidade. Cadernos de Pesquisa. São Paulo: Autores Associados, n. 118, p. 189-205, 2003.

LEFF, E. Epistemologia ambiental. São Paulo: Cortez, 2001.

Pensar a complexidade ambiental. In: LEFF, E. (Org.). A complexidade ambiental. São Paulo: Cortez, 2003.

LÉLÉ, S. Sustainable development: a critical review. World Development. London: Pergamon Press, v. 19, n. 6, 1991.

LIMA, G. Crise ambiental, educação e cidadania. In: LAYRARGUES, P. (Org.). Educação ambiental: repensando o espaço da cidadania. São Paulo: Cortez, 2002.

LOUREIRO, C. Trajetória e fundamentos da educação ambiental. São Paulo: Cortez, 2004.

MARTELL, L. Ecology and society. Polity Press: Oxford, 1994.

McCORMICK, J. Rumo ao paraíso. Rio de Janeiro: Relume Dumará, 1992. caps. 1 a 4.

MOLL, A. From sacracity to sustainability. Frankfurt: Peter Lang, 1991.

MORIN, E. Complexidade e transdisciplinaridade: a reforma da universidade e do ensino fundamental. Natal: Editora da UFRN, 2000.

Ciência com consciência. Rio de Janeiro, Bertrand Brasil, 2002.

et al. Educar na era planetária. São Paulo: Cortez, 2003.

NOBRE, M.; AMAZONAS, M. Desenvolvimento sustentável: a institucionalização de um conceito. Brasília: Edições IBAMA, 2002.

NOOGARD, R. Valoração ambiental na busca de um futuro sustentável. In: CAVALCANTI, C. (Org.). Meio ambiente, desenvolvimento sustentável e políticas públicas. São Paulo: Cortez, 1997.

O'RIORDAN, T. The Politics of Sustainability. In: TURNER, T. (Org.). Sustainable environmental economics and management principles and practice. London: Belhaven, 1993.

REDCLIFT, M. Os novos discursos da sustentabilidade. In: FERNANDES, M.; GUERRA, L. (Orgs.). Contra-discurso do desenvolvimento sustentável. Manaus: Unamaz, 2003.

RUSCHEINSKY, A. Sustentabilidade: uma paixão em movimento. Porto Alegre: Sulina, 2004, p. 15-33.

SACHS, I. Ecodesenvolvimento: crescer sem destruir. São Paulo: Vértice, 1986.

Caminhos para o desenvolvimento sustentável. Rio de Janeiro: Garamond, 2000.

SAUVÉ, L. La educación ambiental entre la modernidad y la posmodernidad: en busca de un marco educativo integrador. Tópicos en Educación Ambiental. México: Semarnap, v. 2, n. 5, 1999.

SEN, A. Desenvolvimento como liberdade. 4. ed. São Paulo: Companhia das Letras, 2004. 
SHENG, F. Valores em mudança e construção de uma sociedade sustentável. In: CAVALCANTI, C. (Org.). Meio ambiente, desenvolvimento sustentável e políticas públicas. São Paulo: Cortez, 1997.

STENGERS, I. Quem tem medo da ciência? Ciência e poderes. São Paulo: Siciliano, 1990.

TRISTÃO, M. As dimensões e os desafios da educação ambiental na sociedade do conhecimento. In: RUSHEINSKY, A. (Org.). Educação ambiental: abordagens múltiplas. Porto Alegre: Artmed, 2002.

VEIGA, J. E. da. Desenvolvimento sustentável: 0 desafio do século XXI. Rio de Janeiro: Garamond, 2005.

Recebido em 19.04 .05

Modificado em 10.06.05

Aprovado em 06.07.05

Pedro Roberto Jacobi é doutor em Sociologia, professor titutlar da Faculdade de Educação e do programa de pósgraduação em Ciência Ambiental da Universidade de São Paulo. É autor de Políticas Sociais e Ampliação da Cidadania (2000), Cidade e Meio Ambiente: percepções e práticas em Sào Paulo (1999), co-autor de Citizens at risk (2001) e coeditor da revista Ambiente e Sociedade. 